
\title{
25 Research Soure \\ Using Citizen Heritage Science to monitor remote sites; a comparison of two methods
}

Rosie Brigham ( $\square$ rosie.brigham.10@ucl.ac.uk)

University College London https://orcid.org/0000-0001-7072-9743

\section{Scott Orr}

University College London

\section{Lyn Wilson}

Historic Environment Scotland

\author{
Adam Frost \\ Historic Environment Scotland \\ Matija Strlič \\ University College London \\ Josep Grau-Bové \\ University College London
}

\section{Research article}

Keywords: Remote monitoring, conservation, surveying, participatory methods, crowdsourcing, built heritage, historic environments, photographic evidence

Posted Date: October 26th, 2020

DOI: https://doi.org/10.21203/rs.3.rs-92596/v1

License: (c) (1) This work is licensed under a Creative Commons Attribution 4.0 International License.

Read Full License 


\section{Abstract}

For large heritage organisations the monitoring and documentation of sites in their care presents considerable challenges; continual monitoring of the smaller, unstaffed and more remote sites is often not practical. Long-term trends, one off events or seasonal variations can sometimes go unnoticed or undocumented. However, heritage sites are often popular tourist destinations and can receive a high level of footfall from visitors who carry increasingly sophisticated mobile phones. It seems a logical conclusion that heritage organisations capitalize on using visitors' images to record and monitor remote heritage sites.

This research proposes Citizen Heritage Science as an effective method to gather reliable data for heritage sites. We compare two methods for data collection: a 'guided' approach, in which on-site signage prompts visitors to submit photographs of specific areas of a site; and an 'open' approach, in which the public is asked to send any photographs they have of the site in question.

At the study sites in Scotland, Machrie Moor and Clava Cairns, the guided approach provided enough images to monitor specific risks to the site (erosion and flooding). Visitors conformed to the instruction provided and the majority of submitted images could be included in the analysis. The open approach was successful in gathering a large number of submissions during the national lockdown in the spring of 2020 in which access was restricted to heritage sites. Notably, the open approach led to more diverse images which was ultimately beneficial, resulting in a multi-faceted understanding of long-term changes in site interpretation and management. Finally, we found great benefit in storing the data in an accessible database; this meant research data was easily accessible for heritage managers in real time, requiring no specialist knowledge for access or analysis. This allowed for rapid responses to urgent one-off events, such as heritage crime.

In summary, both approaches have potential to inform monitoring of heritage sites which would otherwise require significant resources to be more frequently monitored by staff. In presenting both methodologies we hope heritage institutions will be able to set up similar projects and continue research in the field of Citizen Heritage Science.

\section{Introduction}

Citizen science involves enlisting groups of untrained volunteers to participate and contribute to scientific research. Crowdsourcing and citizen science are often used interchangeably however there is a difference between the two. Crowdsourcing involves engaging a group of people within any project that utilises contributions from non-professionals, be it through collecting or analysing data. Citizen Science projects are the same, with the exception that they have a focused scientific outcome and engage nonprofessionals in some point of the scientific process [1,2]. Citizen heritage science is the practice of engaging communities and individuals with scientific understanding of heritage. Examples of this are projects such as Micropasts [3] and Rekrei (formerly Project Mosul) [4], used crowdsourced images to 
create digital facsimiles of heritage artefacts, utilising citizen heritage scientists for both data collection and analysis. Using satellite imagery volunteers helped identify fossils across East Africa as well as pinpoint possible locations for the tomb of Gengis Khan across the Mongolian steppe $[5,6]$.

Citizen science can assist in heritage disaster management and is an effective methodology to understand community values of heritage $[7,8]$. It is also a valuable tool used to transcribe, process and discover myriad types of metadata contained within collections, as can be seen in projects such as Transcribe Bentham, Old Weather, What's on the Menu and Monitoring the ANZACs to name a few [9-11].

Citizen science projects that involve the collecting of data thrive in areas which are closely aligned to popular leisure activities. Participants can contribute to real scientific research whilst maintaining their current hobby. To date the vast majority of CS projects involving data collection are aligned with environmental conservation, such as e-Bird [12] and Budburst [13]. Whilst projects such the Coastal and Intertidal Zone Archaeological Network, otherwise known as CitiZAN, and the Scottish equivalent Scottish Coastal Heritage at Risk have had great success in utilising volunteers to monitor remote heritage sites in danger, there are comparatively few citizen science projects involving collecting data for heritage [14].

Visiting heritage sites is a highly popular pastime in UK; in England 73\% of the population visited a cultural heritage site in 2018 [15] whilst in Scotland 75\% of the population were actively engaged with cultural heritage [16]. This represents considerable untapped potential for monitoring heritage sites: using mobile devices visitors can 'act' as sensors, recording one-off events or ongoing phenomena that would not otherwise be monitored without a regular presence at the site.

Smartphone cameras are capable of monitoring a variety of issues in heritage such as biological growth, erosion and one-off events such as vandalism [17-20]. The vast majority of scheduled monuments across the UK are small, unstaffed and not often visited by heritage professionals but are often destinations for tourists and popular walking sites for locals.

Similarly, when a heritage site is well known and frequently visited, it is likely there is a wealth of useful historical reference data stored in personal photographs. These can be used to qualitatively study the changing use of a site over time, as recently done by English Heritage in the exhibition 'Your Stonehenge, 150 years of personal photographs' [21].

Within heritage science, environmental and observational monitoring is key to ongoing care. However individual object monitoring cannot always be completely uniform; national heritage institutions often have a large portfolio of sites in their care spread over a large geographical area. Smaller and unstaffed sites such as cairns, standing stones and ruined churches often receive comparatively fewer visits from conservation and management teams meaning that long term trends, one off events and seasonal variants can go un-noticed or undocumented.

In this paper we present a methodology developed as part of the citizen heritage science project Monument Monitor as a viable way to collect digital conservation data. It uses photographs taken and 
provided by visitors to monitor specific aspects of heritage sites in Scotland. This utilizes the interested site attendee or 'visitor-as-sensor', to document patterns that may otherwise go unnoticed between visits from professionals.

In this paper we compare two different types of data collection: a 'guided' approach in which participants are directed to take and submit photographs that fit certain specifications through signage and an 'open' approach, in which participants respond to an open call for photographs through public channels. Unlike other Citizen Heritage Science projects, such as SCAPE and CiTIZAN, Monument Monitor does not actively recruit and training volunteers. Instead visitors to the site were prompted to submit digital conservation data (photographs) through signage or press outreach which are subsequently uploaded onto an online database. This interactive database was accessible to all key stakeholders in the project, creating an ongoing live feedback loop for site managers and heritage scientists alike.

\section{Methodology}

\subsection{The project setup}

This paper will focus on submissions from two sites within the Monument Monitor project; Machrie Moor Standing Stone Circles and Clava Cairns. This is due to the higher levels of both open and guided submissions at both sites in comparison to other case studies sites in the project. Both sites have similar demographics, being relatively rural sites and receiving a similar number of visitors per year. This means that difference in the collected data will more likely reflect the data collection method, and not necessarily the site.

Machrie Moor Standing Stones, situated on the Isle of Arran, comprises of six stone circles built around 2000 BCE. Due to the topography of the area the site is prone to flooding, especially in the furthermost and middle circle. Clava Cairns is a bronze age cemetery complex comprising of hut circles, standing stones, chambered cairns and field systems. Situated near to the Culloden Battlefield and being linked to a popular TV series 'Outlander', the site has enjoyed an increase in visitors since 2014. As a result of this area of the site have started eroding noticeably around cairn entrances with visitors even treating the site with light-fingered contempt [22]. As such, heritage managers requested for images to document these areas of the site, as well as any stone movement that may be the result of nighthawkers or vandals.

\subsection{Data pipeline}

A data pipeline was designed to ensure data collected from the project was stored centrally in one location and was easily accessible to both the academic researchers and heritage managers involved in the project. As data was requested from four difference sources, a certain amount of automation was put in place to minimise time spent uploading and categorising through the data. Figure 1 depicts the data pipeline from submission to analysis by the heritage managers. An online database was created to store, sort and subsequently analyse the submitted data. This was built with Ruby-on-Rails with a Postgres SQL database and hosted Heroku. Submitted images were stored on an Amazon Web Services S3 service and 
were linked to the database entries using Active Storage, an extension to the Rails programming framework.

Two programming scripts were run automatically daily to collect posts from both Twitter and Instagram that contained the hashtag \#monumentmonitor, included an image, and was not a re-post. Images submitted via email and WhatsApp were bulk uploaded through an online form. This process ensured that the researcher spent minimal time organising the submitted data; uploading submissions took roughly 45, reduced to 15 minutes during periods of low submission. In accordance with General Data Protection Regulations (GDPR), no personal or identifiable information for any individual was recorded.

In the following analysis each photograph constitutes an individual submission; thus, if one person were to submit 30 photographs it would count as 30 submissions from one participant. Images with unsuitable content, such as those containing faces, were categorised as 'unsuitable' and images in which the site could not be recognised were categorised as 'unidentified'. Duplicate data was also removed at this point; submissions from the primary researcher's personal Twitter and Instagram accounts as well as the main Monument Monitor Instagram account were not included in data analysis. This is because they were re-posts of other submissions, created to publicise the work of the project.

An interactive website was built to allow project stakeholders to easily access the submitted images (Fig. 2). Images were categorised by site and submission type could also be tagged with any relevant observations. The service allowed images containing specific issues to be easily identified by site managers and heritage scientists in real time. This is a key difference to traditional scientific approaches for data storage in which specialised knowledge and access is often required to access research data. Access to submitted images was direct, easy and well-received by project stakeholders.

\subsection{Guided submissions}

Signs were placed at each site to prompt visitors to take and submit photographs to the project, using either email, WhatsApp, Twitter or Instagram (Fig. 3). Visitors were prompted to use the hashtag '\#monumentmonitor' alongside the name of the site to assist in identification. Individual signs were created for each location, as different aspects were to be monitored at each site. Different wording was used for each sign, chosen in discussion with site managers focusing on a specific issue. At Machrie visitors were requested to document groundwater flooding, the reoccurrence of which is currently undocumented. Signs were placed at the entrance of circle 3 and 6 and visitors were requested to 'take a photo of the circles from the sign', thus giving some degree of unity to the submitted images.

At Clava Cairns the instructions were vaguer, the manager was keen to see how visitors experience the site as well as document any stone disturbance. As such, visitors were asked to take photos of the cairns 'from different angles' to 'monitor the effects of ground erosion, graffiti and stones being moved'.

\subsection{Open submissions}


Following the UK wide lockdown arising from the COVID-19 pandemic, a public campaign, 'Monument Monitor at Home' was started which requested members of the public to submit any photographs they had of the case study sites. Started with a blog published by HES on the 14th August [23], with ten articles published in a variety of national newspapers and three articles in history magazines [24, 25]. These were complemented by a social media push from the ISH, UCL SEAHA and HES twitter accounts. There was a particular focus on Clava Cairns and Machrie Moor Standing Stone Circles as it was more likely that the general public would have heard of and visited them. It was found that Clava Cairns was of particular media interest, due to the connection with the television show 'Outlander' [26]. As such, the majority of the press coverage garnered from the campaign focused on Clava, which is also reflected in the submission results.

\subsection{Relevance of submissions}

As Ma et al. commented, an advantage of using citizen scientists to collect data is that it does not necessarily matter if most images are unusable, as long enough are submitted in the required time scale [27]. Thus, in order to establish the percentage of useable images, each image was categorised based on if it was useful for monitoring purposes in discussion with site managers. Alongside any images showing one-off events, photographs of Clava Cairns had to contain a clear view of either cairn entrance in order to effectively measure ground erosion at the site. At Machrie, relevant images had to include a clear view of the 3rd and 6th circles in the complex, in order to monitor levels of groundwater flooding.

\section{Results}

Guided submission numbers were related to the seasonal trends of tourism in Scotland and wider national guidelines during the COVID-19 pandemic. Submissions steadily accumulated once the signs were placed on-site, as seen in Fig. 4. The popularity of Machrie Moor, the final sign to be installed, is evident by the spike in submissions through September and October, a popular time for visitors being the off-peak 'shoulder season' for tourism in Scotland. February 2020 saw successive storms across the country and less data was submitted than in the previous month. Participation started to rise throughout March 2020 but was quickly curtailed on the 16th when the UK government advised against all nonessential travel amidst the COVID-19 global pandemic. Ticketed sites were shut to stop the spread of COVID-19 and on 23 March 2020 a nationwide lockdown was imposed. The effect of diminished submission levels can clearly be seen in Fig. 4, especially when comparing guided submissions between June 2019 and the spring of 2020. Though Scottish Government guidance permitted outdoor exercise once per day, people could not travel over 5 miles for leisure until 3 July. As such, throughout the lockdown period, the only guided submissions received were from sites that were unstaffed and situated in more urban areas i.e. those which were readily accessible. Being quite remote, Machrie Moor and Clava Cairns received considerably less submissions than other properties in the project that were near urban centres. In addition, rates of submission via social media channels dropped considerably, with $25 \%$ of submissions being made through social media, down from $39 \%$ pre-lockdown. 
The Monument Monitor at Home campaign was launched on the 14th April 2020 with a blog and successive articles in the national press. As Fig. 5 shows, this led to a $10 \%$ increase in overall submissions, the majority of which were historical photographs. Whilst guided submissions are often sent in within weeks of being taken, most of the open submissions were many years old, shown in Fig. 6 . Though dependant on the wording of the campaign request, this indicates the usefulness of the open method for gathering historical data. However, open submissions relied heavily in public engagement through traditional media channels. Figure 5 shows high levels of submission after each publication which quickly dwindled.

Relevant submissions at both sites were of high enough frequency to carry out subsequent monitoring and analysis. Comparatively fewer overall submissions for Clava were considered relevant, with roughly $4 \%$ of both open and guided submissions (Fig. 6). At Machrie Moor however, the split is much larger. Considerably more guided images were appropriate for analysis $(26.3 \%)$ whilst only $1.7 \%$ of open submissions were relevant.

Participants often submitted multiple photographs for each site, and guided submissions would often feature the more 'picturesque' features of the site, along with aspects prompted through signage. This means that the overall percentage of relevant submissions is low for both sites. However, the majority of participants submitted at least one relevant photograph for analysis. The exception is for open submissions at Machrie Moor, for which only $3.8 \%$ were relevant.

The project successfully alerted managers to numerous instances of heritage crime and natural disasters. The pilot project, which ran in 2017 notified managers regarding an incident of graffiti at Machrie Moor, in which a visitor had carved their initials into the Neolithic monument. In August 2020 a tree fell onto one of the chambered cairns during a storm, which was subsequently reported the next day. At several other Monument Monitor sites littering, stone movement and damaging campfires have also been reported. In each of these cases, there was not a scheduled visit from a conservation professional planned for at least a week.

There were also several submissions reporting a heritage crime which actually were far from it. Numerous photographs submitted of Machrie Moor were from visitors worried that stones have been moved from the site. After an investigation it was found that the culprit was a local sheep, who had scratched a hole into the floor to shelter from the wind. Improved signage is now being considered to reassure visitors.

\section{Discussion}

Digital documentation is a vital part of preventative conservation and offers a sustainable and scalable approach to the registration and management of conservation information [28]. While pioneering activities such as the RAE project in Scotland [29] and HeritageCare [30] in southern Europe are leading examples of large-scale digital conservation methodologies, they rely heavily on professionals providing all documenting and monitoring data. Using this methodology heritage institutions can capture long-term trends and one-off events between site visits from conservation professionals. This is a novel method of 
scientific investigation within heritage and is particularly pertinent immediately following the coronavirus pandemic and can be used to supplement other methods of documentation that cannot be carried out due to national or local restrictions, such as those caused by the COVID-19 global pandemic.

Visitors responded positively to the requests to send in data, both on site and from press outreach. The open method is well suited for gathering historical data. Open submissions from Clava Cairns dated back to the 1960's and clearly showed visitors enjoying the site through the subsequent decades. These submissions have provided the site managers with a valuable visual historical resource; they visually record different management approaches that are otherwise missing from conservation records.

The open method also proved to be a useful catalyst to engage the public at a time in which heritage sites were inaccessible to many. Many images were submitted with fond memories and anecdotes about their visit as well as consternation about the issues they faced - particularly erosion across Clava Cairns. This methodology has a double positive by engaging communities with the conservation issues alongside collecting reference data. Similar outreach often helps ascertain the social value of heritage [31-33], and can be used within a toolkit of other approaches [34]. Whether this methodology could be used with or alongside such a toolkit requires further research.

The sign at Clava requested for images to be taken 'around the site, including any stone disturbances', which alongside monitoring erosion would potentially provide an early warning mechanism to instances of vandalism [22]. This is why the relevance is low for both open and guided methods. Submissions were general photos that people took around the site. The cairn entrances at Clava are particularly 'picturesque', and so often feature in visitor photographs shown in Fig. 6.

Machrie has a much higher level of 'relevant' guided submissions than of Clava, this is likely due to the signage at having more specific instructions. The sign at Machrie requested images of two specific circles in order to monitor waterlogging. The area of the site being monitored, Circle 6 , is not most 'picturesque' viewpoint of the site. Being somewhat removed from the main standing stones circles visitors sometimes fail to reach it all together. As such, historical holiday snaps rarely capture the area and was featured in only $1.7 \%$ of open submissions, whilst $26 \%$ of guided submissions did feature the circle which was sufficient to measure weekly fluctuations in waterlogging. Therefore, both open and guided approaches are useful if the aspect to be monitored is a part of the 'standard' visitor image. However, a guided approach is more suitable where specific images are required.

The open method relies heavily on public outreach and is particularly resource-intensive in all aspects of publicity, media and social media management. This should be factored into citizen heritage science projects. Much less engagement is needed for the guided method as the signage is the catalyst for submission. Whilst submission numbers through the open method were high, guided submissions are more sustained and is more suited for ongoing monitoring.

The project successfully alerted the conservation team to numerous issues across the sites including two instances of heritage crime (vandalism and illegal camping) and several instances of littering. In early 
August several submissions alerted the management team to a tree that had fallen on the southern cain at Clava, which was quickly removed by conservation staff. In each of these instances the site was not scheduled for a visit, demonstrating the effect of the visitor-as-sensor. Site managers and project stakeholders were able to easily access the submissions and use them for their own analysis of ongoing trends at the site.

\section{Conclusion}

Both a 'guided' and 'open' approach to citizen heritage science provides useful data for heritage managers and other stakeholders, which has been summed up in table one. As a multidisciplinary approach it can help with both scientific and heritage management questions. Guided images were submitted with enough frequency to monitor aspects such as erosion and flooding at both sites. The visitor-as-sensor successfully discovered numerous instances of events that would otherwise have gone un-checked between routine inspections. These could be acted upon in a swift manner due to the data pipeline that allowed heritage managers access to the research data in real time. Whilst the COVID-19 pandemic negatively impacted the frequency of guided submissions, the open approach to data collection proved adequate at providing site managers with useful insights pertaining how sites are enjoyed and managed at a time where access to heritage was restricted at an unprecedented level.We believe there is much scope for future citizen heritage science projects and present this paper as a methodology for heritage institutions to set up similar projects and conduct further research.

\section{Declarations}

\section{Data Availability}

The Monument Monitor dataset used and analysed during the current study are available from the corresponding author on reasonable request.

\section{Competing interests}

The authors declare that they have no competing interests

\section{Funding}

This research was joint funded by the Engineering and Physical Sciences Research Council (grant number EP/L016036/1) and Historic Environment Scotland.

\section{Authors contributions}

Rosie Brigham; conception, design, analysis, writing

Scott Orr; project design, contribution to the manuscript 
Adam Frost; project design (digital documentation

Matija Strlič; contribution to the manuscript

Lyn Wilson; project design (digital documentation and heritage management), contribution to the manuscript

Josep Grau-Bové; contribution to the manuscript, editing, principal investigator

\section{Acknowledgments}

The authors wish to acknowledge the ongoing support of the staff at Historic Environment Scotland, particularly in the communications, conservation and management teams.

Special thanks to Hugh Boag, Ryan Taylor and George Mair for their work in publicising Monument Monitor at Home.

The authors wish to thank all participants in the Monument Monitor project, without whom this work not be possible.

\section{References}

1. Blaser L. Old Weather: Approaching Collections from a Different Angle. In: Ridge M, editor. Crowdsourcing Our Cult Herit. Routledge; 2014. p. 45-56.

2. Heigl F, Kieslinger B, Paul KT, Uhlik J, Dörler D. Opinion: Toward an international definition of citizen science. Proc Natl Acad Sci U S A [Internet]. National Academy of Sciences; 2019 [cited 2019 May 14];116:8089-92. Available from: http://www.ncbi.nlm.nih.gov/pubmed/31015357.

3. Bonacchi C, Bevan A, Pett D, Keinan-Schoonbaert A, Sparks R, Wexler J, et al. Crowd-sourced Archaeological Research: The MicroPasts Project. Archaeol Int. 2014.

4. Vincent ML, Gutierrez MF, Coughenour C, Manuel V, Bendicho L-M, Remondino F, et al. Crowdsourcing the 3D digital reconstructions of lost cultural heritage. 2016.

5. Wilson A. Fossil Finder blog [Internet]. 2018 [cited 2019 May 8]. Available from: https://www.zooniverse.org/projects/adrianevans/fossil-finder/about/results.

6. Lin AY-M. The search for Genghis Khan: Using modern tools to hunt for an ancient past. 2010.

7. Kumar P. Crowdsourcing to rescue cultural heritage during disasters: A case study of the 1966 Florence Flood. Int J Disaster Risk Reduct. 2020.

8. Kyi C, Tse N, Khazam S. The potential role of citizen conservation in re-shaping approaches to murals in an urban context. Stud Conserv. 2016.

9. Causer T. Terras M. "Many Hands Make Light Work. Many Hands Together Make Merry Work": Transcribe Bentham and Crowdsourcing Manuscript Collections. In: Ridge M, editor. Crowdsourcing Our Cult Herit. New York: Routledge; 2014. pp. 57-68. 
10. Romeo F, Blaser L. Bringing Citizen Scientists and Historians Together. Museums Web 2011 Int Conf Cult Herit on-line. 2011.

11. Ridge M. Introduction. Crowdsourcing Our Cult Herit. 2014. p. 1-13.

12. Kelling S, Johnston A, Hochachka WM, lliff M, Fink D, Gerbracht J, et al. Can observation skills of citizen scientists be estimated using species accumulation curves? PLoS One. Public Library of Science; 2015;10.

13. Johnson KA. Real Life Science with Dandelions and Project BudBurst. J Microbiol Biol Educ. 2016.

14. Hambly J. Scotlands Coastal Heritage At Rist, Final Evaluation Report [Internet]. 2017. Available from: http://scharp.co.uk/media/medialibrary/2017/09/SCHARP-HLF-EVALUATION_FINAL_web.pdf.

15. Department for Digital Culture Media and Sport. Taking Part Survey, 2017/19: quarter 4 statistical release. 2018.

16. Director-General Education C and J. Scottish household survey 2019: annual report. 2019.

17. Harley MD, Kinsela MA, Sánchez-García E, Vos K. Shoreline change mapping using crowd-sourced smartphone images. Coast Eng. 2019.

18. Brigham R, Grau-Bové J, Rudnicka A, Cassar M, Strlic M. Crowdsourcing as an Analytical Method: Metrology of Smartphone Measurements in Heritage Science. Angew Chemie - Int Ed. 2018;57.

19. Wess T. Smartphone citizen science: Can a conservation hypothesis be tested using non specialist technology? Herit Sci [Internet]. 2017; Available from:

https://heritagesciencejournal.springeropen.com/articles/10.1186/s40494-017-0148-z.

20. Barbero-Alvarez MA, Menéndez JM, Rodrigo JA. An Adaptive Colour Calibration for Crowdsourced Images in Heritage Preservation Science. IEEE Access. 2020;1.

21. Your S. 150 years of personal photos. English Herit. 2019.

22. BBC. Vandalism at ancient Clava Cairns burial site [Internet]. BBC News Online. 2017 [cited 2020 Aug 21]. Available from: https://www.bbc.co.uk/news/uk-scotland-highlands-islands-40171195.

23. Brigham R. How your holidays snaps could help historic sites [Internet]. Hist. Environ. Scotl. Blog. 2020 [cited 2020 Sep 29]. Available from:

https://blog.historicenvironment.scot/2020/04/monument-monitor-2/.

24. Lockdown project: Monument Monitor. Hist Scotl [Internet]. 2020; Available from: https://www.historyscotland.com/exclusive-content/lockdown-project-monument-monitor? postld=d3d30df1-6bb5-41f0-8020-a63d0bac4bac.

25. Boag H. Help monitor Machrie heritage site from home. The Arran Banner [Internet]. 2020 Apr; Available from: https://www.arranbanner.co.uk/2020/04/17/help-monitor-machrie-heritage-sitefrom-home/.

26. Mair G. Past of Clava Cairns, Craigh na Dun in Outlander, to be pieced together with visitor snaps. The Sunday Times. 2020 Apr.

27. Ma W, Walton M, Cossairt O, Bearman G, Doehne E. Crowd-sourced mobile phone images for heritage conservation monitoring. Digit Herit 2015. 2015;4. 
28. Jouan P, Hallot P. Digital twin: Research framework to support preventive conservation policies. ISPRS Int J Geo-Information. 2020.

29. Historic Environment Scotland. The Rae Project [Internet]. 2020 [cited 2020 Aug 20]. Available from: https://www.engineshed.scot/about-us/teams/digital-documentation-and-digital-innovation/the-raeproject/.

30. Masciotta MG, Morais MJ, Ramos LF, Oliveira DV, Sánchez-Aparicio LJ, González-Aguilera D. A Digital-based Integrated Methodology for the Preventive Conservation of Cultural Heritage: The Experience of HeritageCare Project. Int J Archit Herit. 2019.

31. Jones S, Leech S. Cultural Value. Valuing the Historic Environment. AHRC Cult. Value Proj. 2015.

32. Jones S. Wrestling with the Social Value of Heritage: Problems, Dilemmas and Opportunities. J Community Archaeol Herit. 2017.

33. Bonacchi C, Bevan A, Keinan-Schoonbaert A, Pett D, Wexler J. Participation in heritage crowdsourcing. Museum Manag Curatorsh [Internet]. Routledge; 2019;34:166-82. Available from: https://doi.org/10.1080/09647775.2018.1559080.

34. Robson E. "Assembling" Future Practice: Multi-Method Approaches to Social Value Assessment. Assoc Crit Herit Stud 2020 Futur Conf. 2020.

\section{Tables}

Table 1

Summary of findings through open and guided methods

\begin{tabular}{|llll|}
\hline & Guided & Open & Further Research \\
\hline $\begin{array}{l}\text { Data } \\
\text { Quality }\end{array}$ & $\begin{array}{l}\text { High, with largest } \\
\text { proportion of 'useful' } \\
\text { images for analysis. }\end{array}$ & $\begin{array}{l}\text { Less high, unless the } \\
\text { area being monitored } \\
\text { is particularly } \\
\text { 'picturesque'. }\end{array}$ & $\begin{array}{l}\text { Useful for one off events } \\
\text { and certain types of } \\
\text { environmental monitoring. } \\
\text { But what are the limits of } \\
\text { this data? }\end{array}$ \\
\hline Frequency & $\begin{array}{l}\text { Of high enough frequency } \\
\text { during tourist low season, } \\
\text { however, very low during } \\
\text { national lockdown and } \\
\text { winter. }\end{array}$ & $\begin{array}{l}\text { Initially high levels of } \\
\text { interaction after press } \\
\text { coverage, that quickly } \\
\text { curtail. }\end{array}$ & $\begin{array}{l}\text { How would different types } \\
\text { of heritage sites affect the } \\
\text { frequency? }\end{array}$ \\
\hline Information & $\begin{array}{l}\text { Successful for reporting of } \\
\text { one-off events, such as } \\
\text { vandalism. }\end{array}$ & $\begin{array}{l}\text { Useful for historical } \\
\text { reference, especially to } \\
\text { see how visitors } \\
\text { experienced the site in } \\
\text { the past. }\end{array}$ & $\begin{array}{l}\text { Can either of these } \\
\text { methodologies be used to } \\
\text { ascertain social values of } \\
\text { heritage? }\end{array}$ \\
\hline
\end{tabular}

\section{Figures}




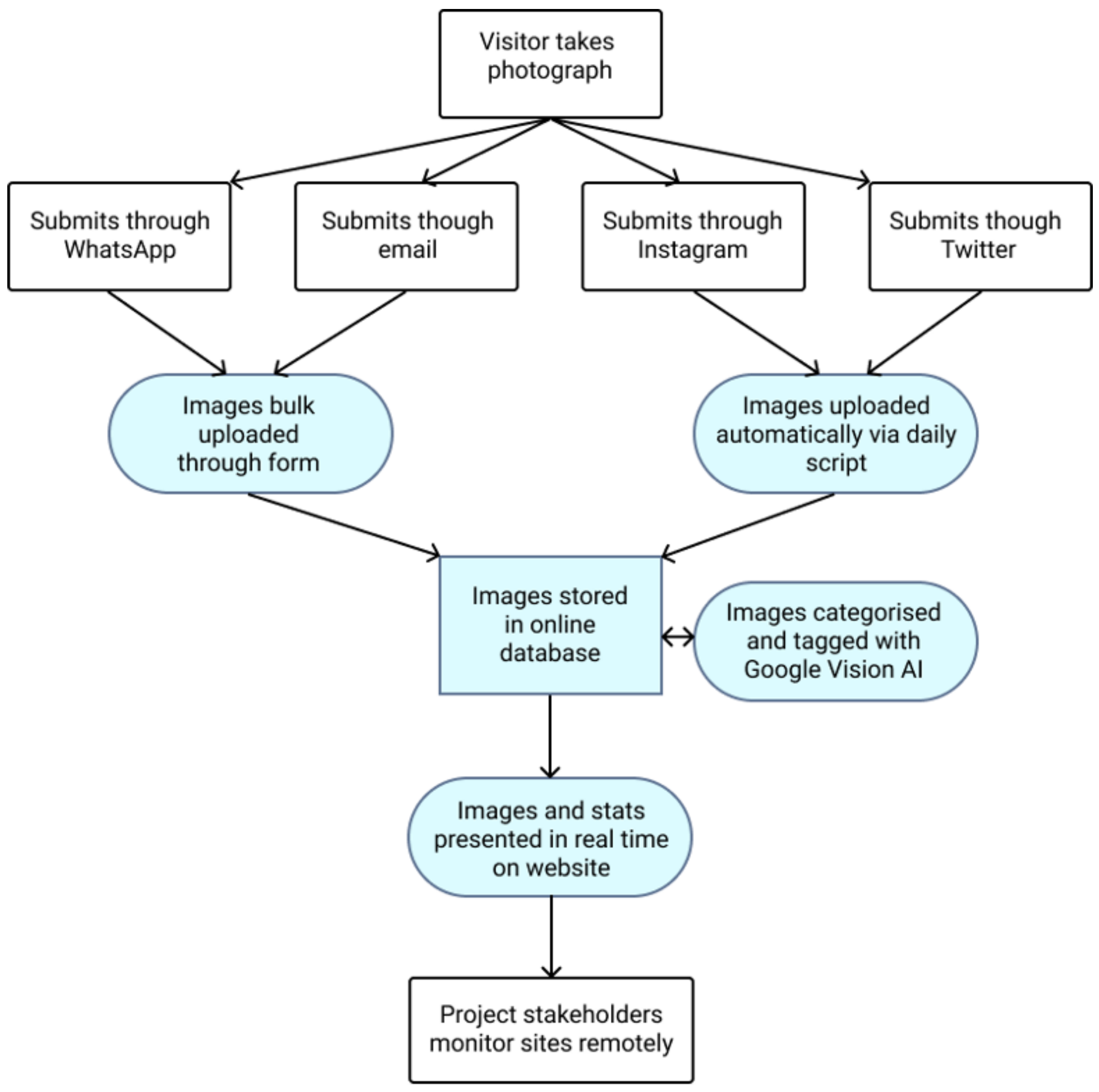

Figure 1

Diagram of data workflow from submission of photograph from visitor to analysis by project stakeholders 


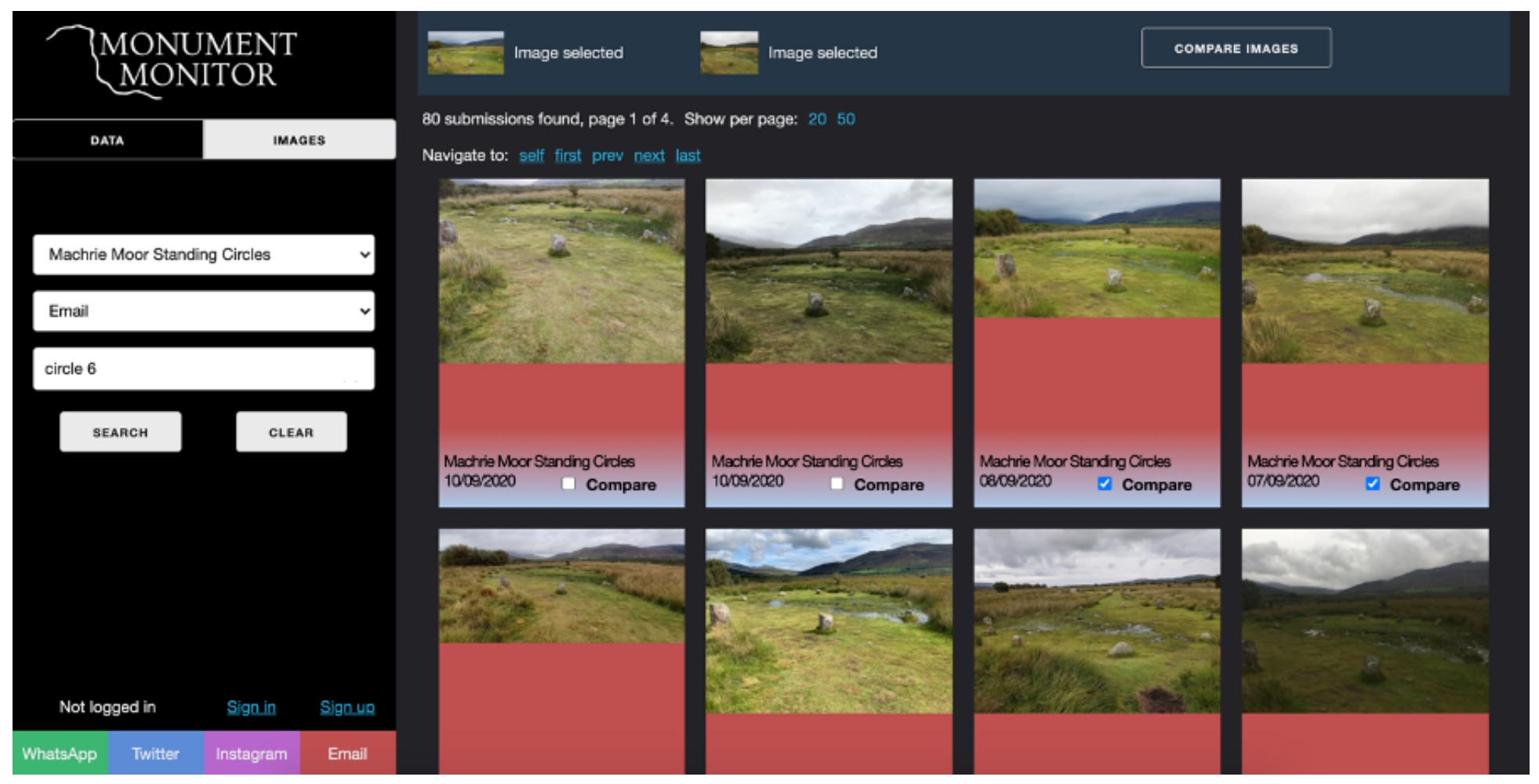

Figure 2

Screenshot of interactive database developed for researchers and site managers. The database allowed users to sort by site, submission type or tag as well as download selected images to a zip file, view submission patterns over the year and compare two sets of images.

\section{Become a citizen scientist and help us monitor groundwater levels at Machrie Moor}

I. Take a photograph of the circle from this sign, without using a filter.

2. Send us your image: Tweet or Instagram using hashtags

"monumentmonitor and "machrie, email it to

submissions@monumentmonitor.co.uk, or

WhatsApp it to $\$ 47909608164$.
We are monitoring the groundwater levels at Machrie Moor as a part of our conservation stragegy for this Neolithic site. Please help us by sending us a picture of your visit.

This is part of the Monument Monitor project, which looks at how we can use visitors' images to assist with conservation monitoring.

Sound interesting?

Visit monumentmonitor.co.uk for further details.

\section{How we use your data}

By submitting an image you agree to let us use it for the purpose of this study. We will annonymise all data submitted and will not contact you further. For further information about the project, how we use your images and all things GDPR, please visit our website at monumentmonitor.co,uk/gdpr.

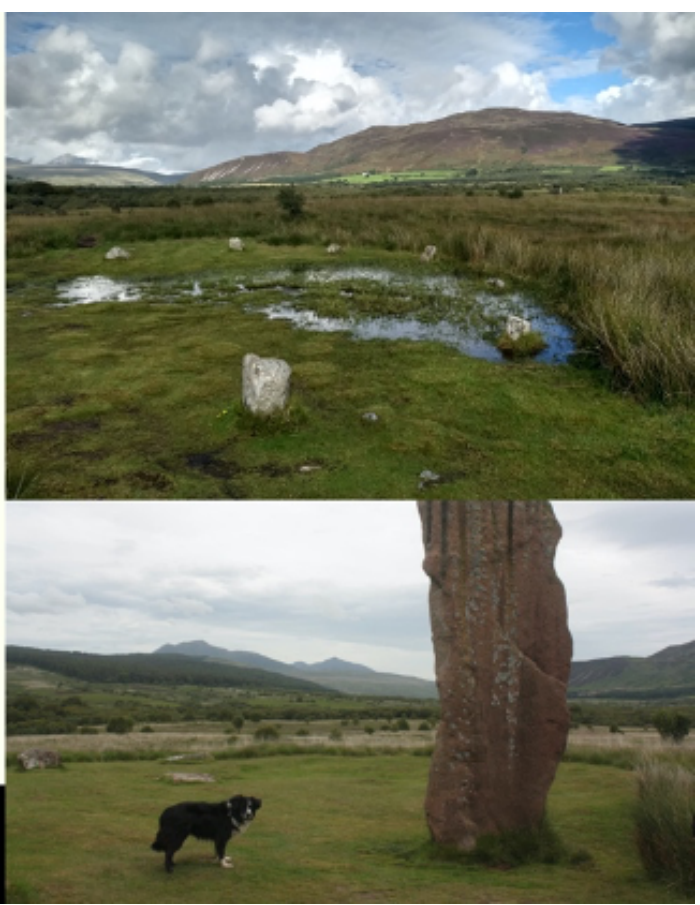

\section{Figure 3}

Example of guided signage, alongside two example submissions, one 'useful' one not. 
Submissions

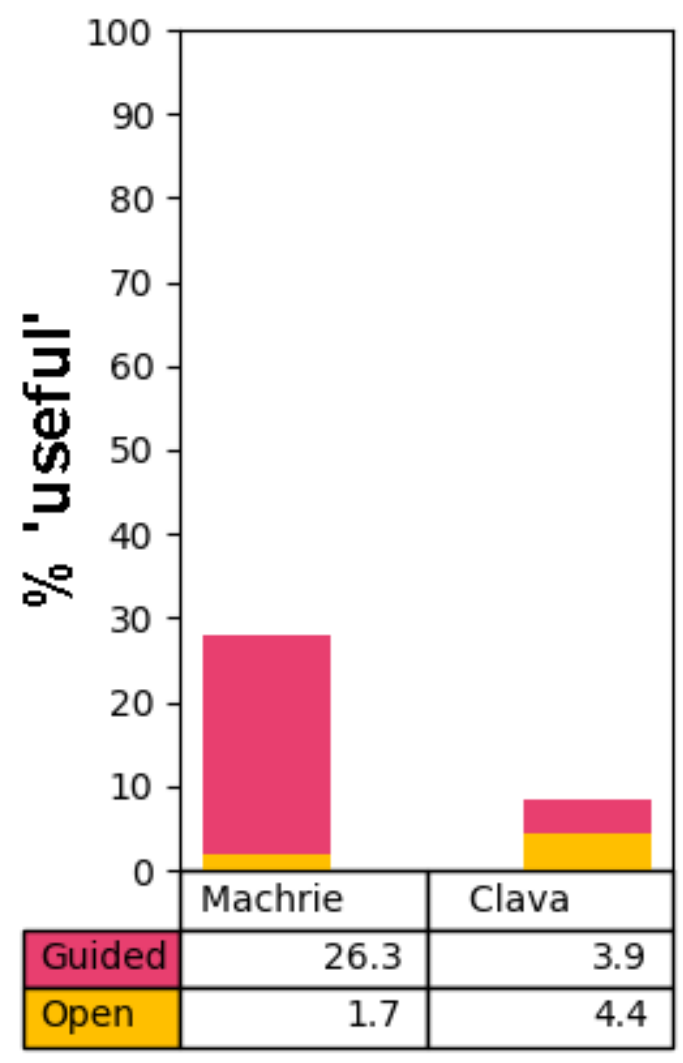

\section{Participants}

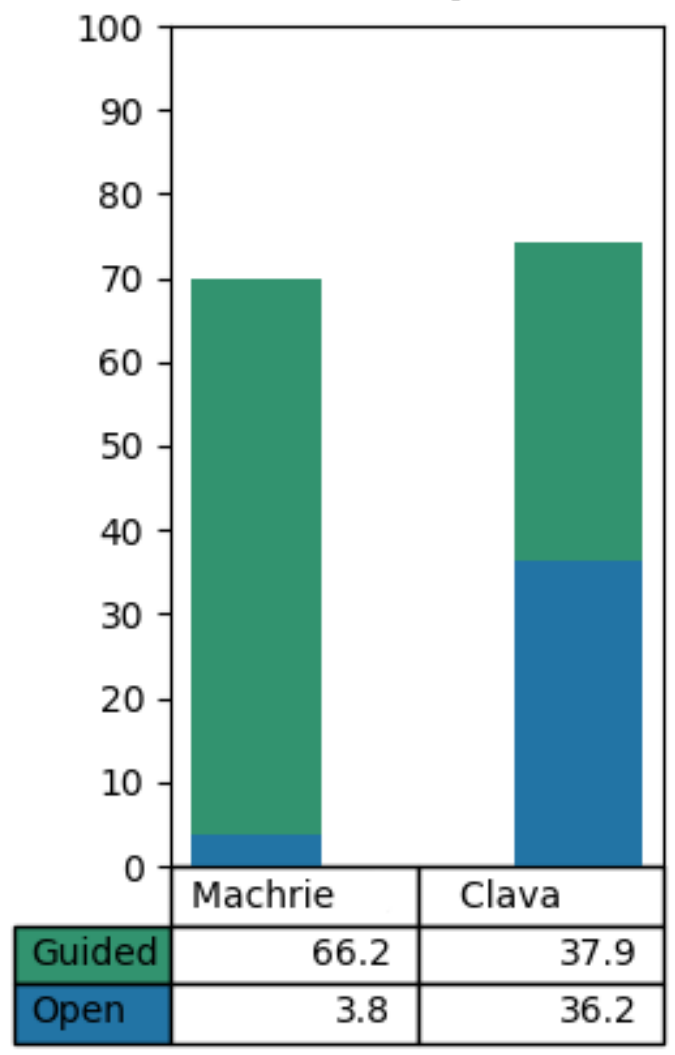

Figure 4

Submission and participation rates at Clava and Machrie showing low numbers of submissions through the winter of 2019 and spring of 2020 when the national lockdown was introduced 


\section{Machrie Moor Stone Circles}

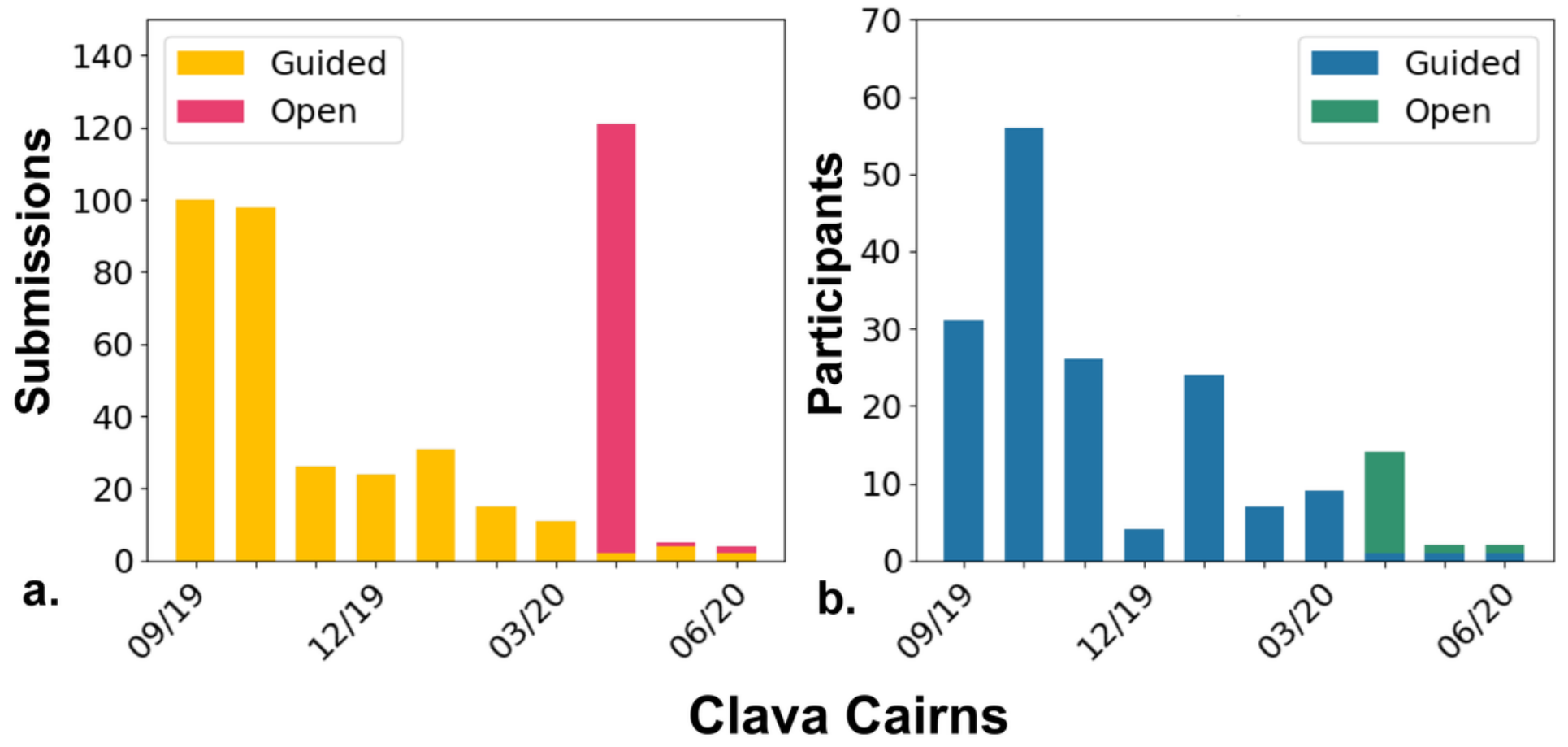

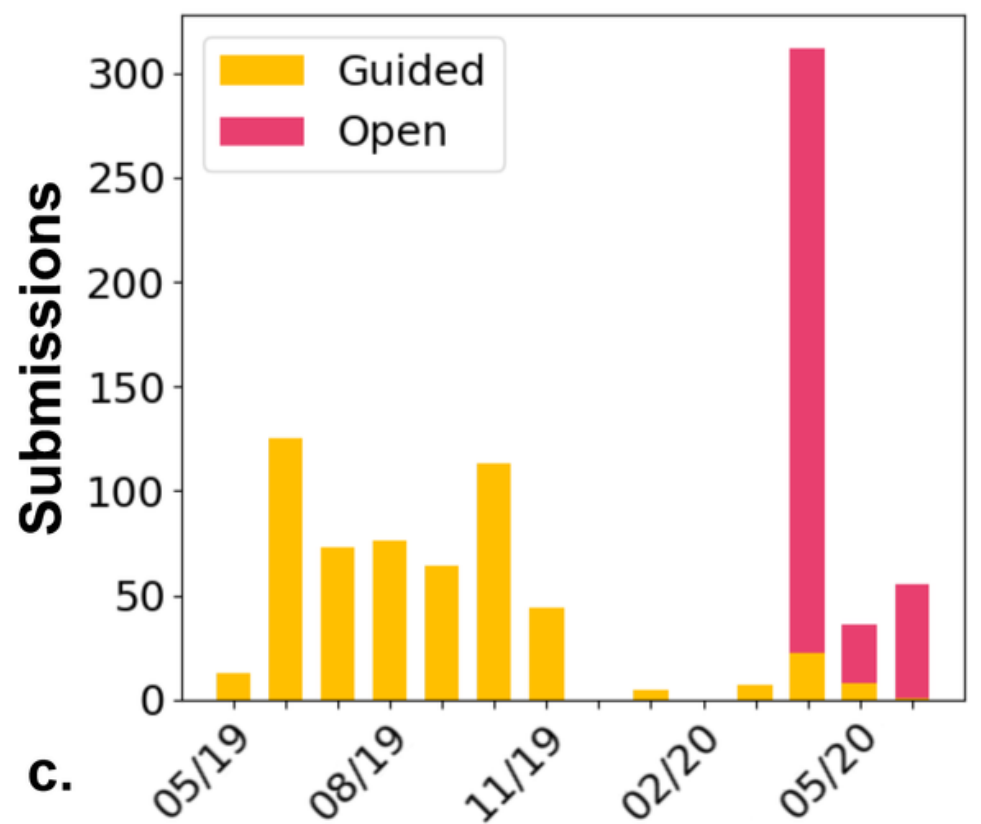

Date submitted

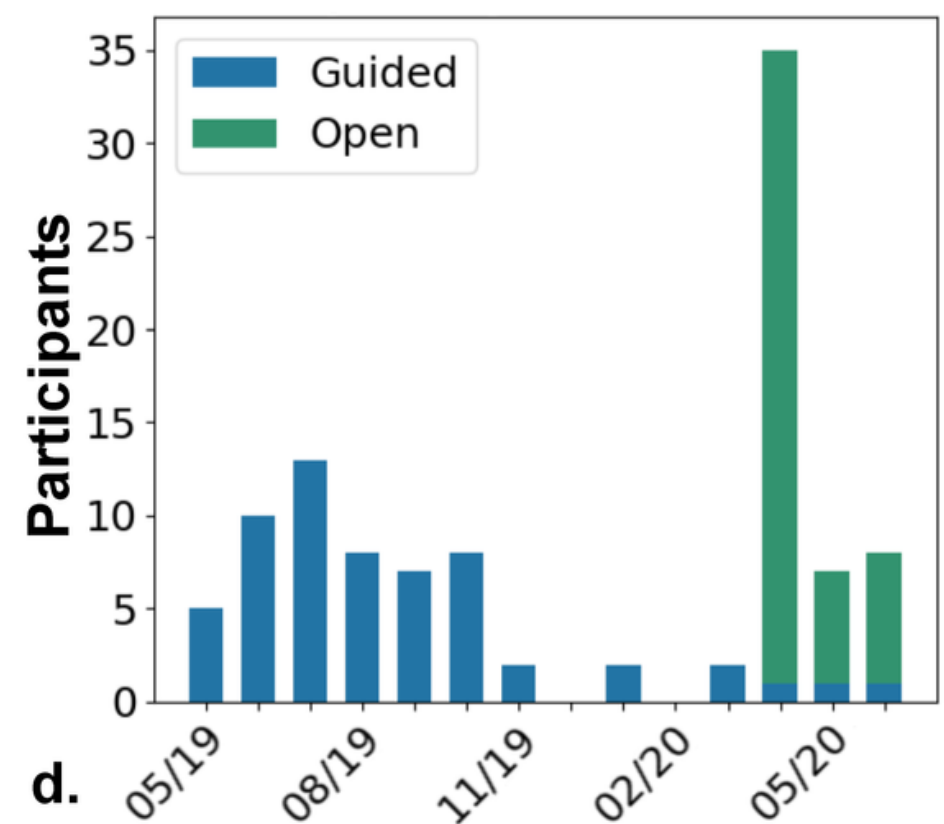

Date submitted

Figure 5

Submissions over spring 2020 lockdown period with press publication dates showing large number of submissions immediately following press coverage. 


\section{Submissions during lockdown}

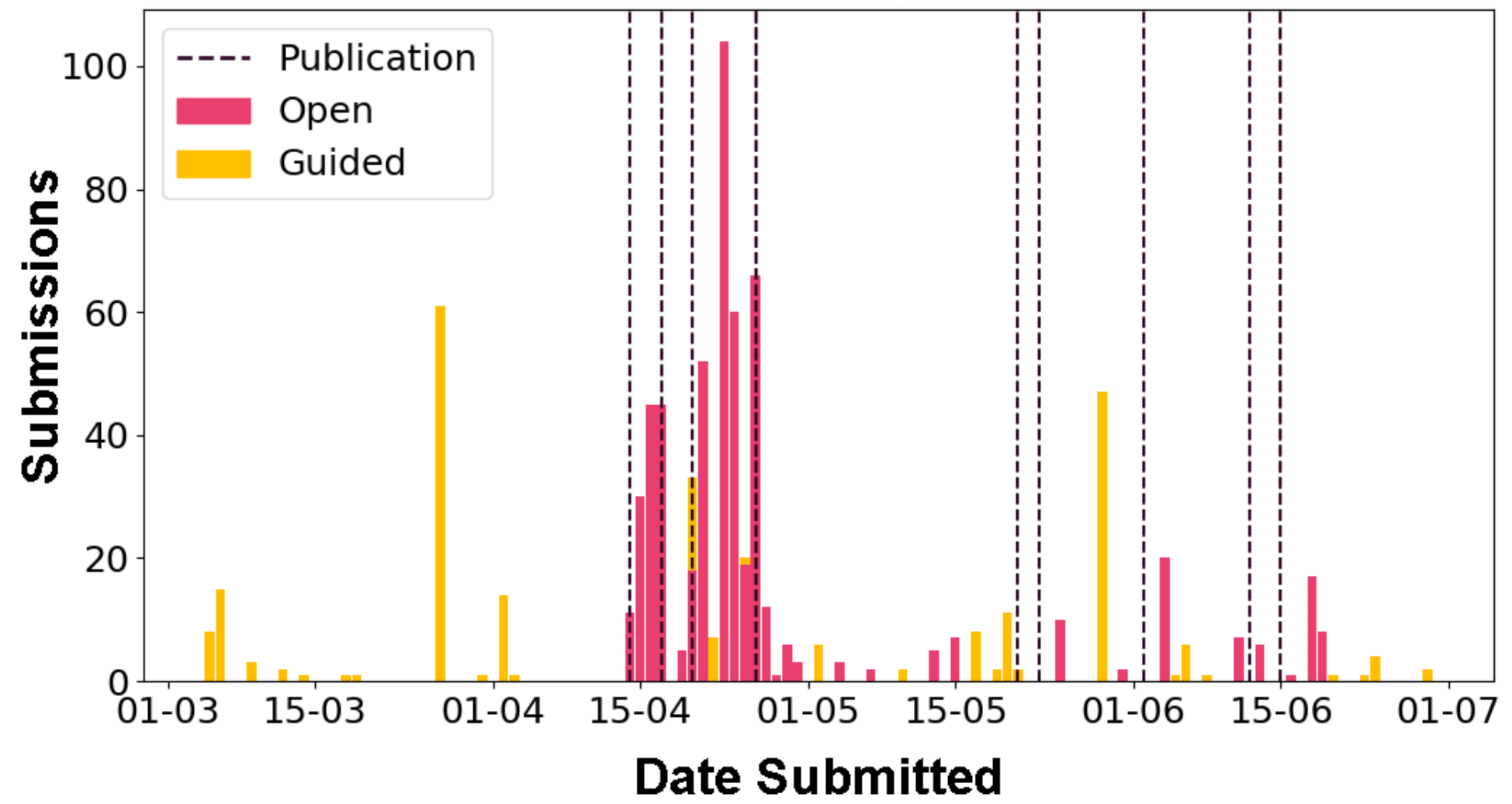

Figure 6

Time passed between site visit and photo submission between open and guided approaches. Open images are often submitted after a much longer period of time than guided. 

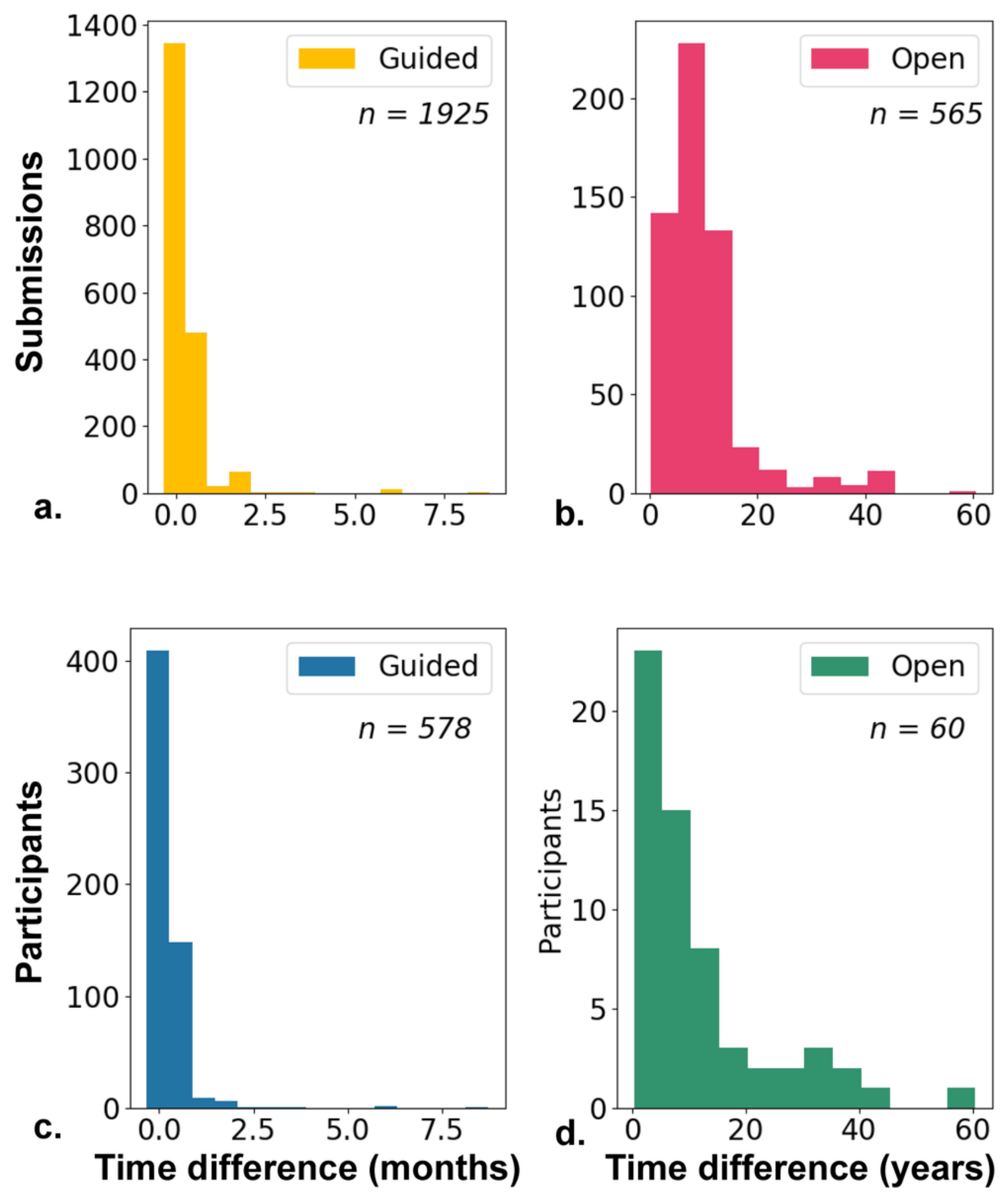

Figure 7

Perceived 'usefulness' of images showing that guided submissions have a higher rate of perceived 'usefulness', as judged by site managers. 